\title{
Relations- and task-oriented behaviour of school leaders: Cases from primary schools in Finland
}

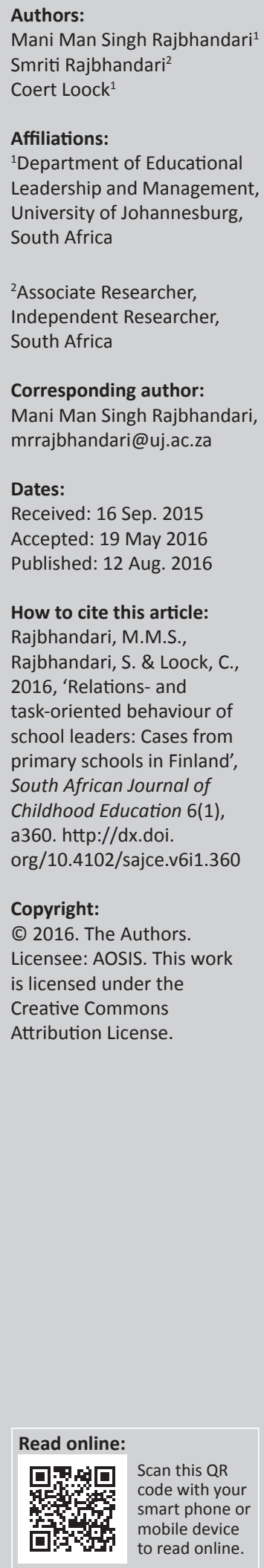

This research explores and compares two leadership behavioural styles - relations- and taskoriented behavioural styles - of school leaders in Finland. This study aimed to explore and understand the behavioural style of school leaders, specifically related to relations-oriented and task-oriented behaviour. Three schools in Finland were selected. In-depth interviews were conducted with school principals, as school leaders, and other school actors, such as vice principals, teachers, special-education teachers, and administrative staff members. The results suggest that leadership behavioural styles in terms of relations-oriented and task-oriented behaviour are equally important for accommodating changes and development in schools. The results suggest that relations-oriented behaviour was preferred by those who had been in the organisation for a longer time. The task-oriented behavioural style was found to be adopted when changes were required by the municipality (school district), which needed to be urgently addressed to meet the current requirements for school infrastructural development and changes in the educational system. In addition, the school leaders with task-oriented behaviour were more effective, while leaders with relations-oriented behaviour were efficient and generated social harmony. These findings suggest that contextual variations enabled flexibility in leadership behavioural style.

\section{Introduction}

The Finnish school system has a history of success. However, growth and development within the educational system can be challenging, especially when school leaders work with well-qualified teachers. Although implementing educational and school management policies can be challenging, school leadership competences can offer a variety of roles by using 'practical intelligence' (Sternberg 1985) and practical wisdom, or phronesis, to generate leadership maintenance through 'psychological, sociological and physiological (PSP) parameters' and by generating a 'mirror effect' (Rajbhandari \& Rajbhandari 2015) to create conducive environments in schools to which the leadership behavioural style of relations and task-oriented behaviour also subsequently contribute.

To be a qualified teacher in Finland, a teacher must have a qualification of master's degree to teach for grade one, which starts at the age of seven (Sahlberg 2010). Small-sized classes are guided by more than one teacher, and sometimes three to four teachers are available in a classroom at any one time. This teaching team includes the special-education teacher and supportive teachers. These team players are organised by the school principal. This arrangement has, in many ways, enabled the Finnish educational system to achieve outstanding success.

However, leadership effectiveness is evaluated by its ability to manage time, tasks, individuals, groups, and situations. This paradigm is closely linked with Sergiovanni's (1990) philosophy of transformational leadership, which comprises the notion of building, bonding, and banking. We would argue that building and bonding could relate to a relational approach, whereas banking leans towards a task-oriented approach or leadership practice.

Furthermore, school leadership readiness should include flexibility and mobility in practice as a primary competence. Our view is, furthermore, that competence in prudency and pragmatic endurance, practised by a school leader, can be achieved by building teams of individuals with task, bonding the team with relations, and banking intelligently.

Leadership behavioural theory came into being after the traits theory of leadership. The traits theory was insufficient and inconclusive in measuring the leadership discourse (Bass \& Stogdill 1990; Bolden et al. 2003). The leadership behavioural theory was highly successful by corresponding the leader's behaviour. Because leadership behavioural theory focused entirely on the leader's 
behaviour, this theory gained ground by offering a leadership paradigm for organisational employees, which has remained its strength, though it also has weaknesses (Derue et al. 2011). The leadership behavioural theory ignored the perceptions of followers' reactions and readiness. Although the theory lacks a paradigm of followers, our study has included a discourse on followers in order to capture the added strength of a paradigm of both the leader and followers. This, furthermore, enabled us to measure the balance of relations and task-oriented behavioural pattern.

The leadership behavioural theory developed at Ohio State University by Stogdill and researchers in 1945 exhibited two types of behaviour, namely people-oriented (consideration) and task-oriented (initiating structure) to enable the accomplishment of organisational goals (Stogdill 1959). In the same vein, the study at the University of Michigan by Likert and researchers in 1947 identified two types of leadership behaviour, namely employee oriented and production oriented (Bass 2008; Likert 1967). These two studies coincided on leadership behaviour for organisational effectiveness, and offered similar views on leadership behaviour. These two behavioural styles were later generalised as relations- (consideration and employees centred) and task-oriented (initiating structure production oriented) behaviours.

In this regard, Northouse (2010) also discusses two behavioural styles, namely relations-oriented and taskoriented behaviours. These styles were incorporated into the Ohio State University work and described in a study by Stogdill in 1945 and at the University of Michigan by Likert in 1947 (Bass 2008; Likert 1967). Based on these studies, the authors proposed the theory of leadership behaviour. In this paper, however, a leadership behavioural pattern of collaborating tasks and relations is applied in the context of an environmental setting that enables the leaders to implement practical intelligence (Sternberg 2000) to act as the situation demands, and to utilise their experience and practical wisdom. This, we would argue, enables the leadership to demonstrate effective behaviour for relations building and task achievement. As stated by Yulk (2008:5), 'effective leaders look for behaviours and programs that are mutually compatible and likely to create synergies rather than adverse side effects'. Thus, school leadership effectiveness is likely to increase performance in teacher and student achievement.

The Appalachia Educational Laboratory (2005:4) states that 'principal behaviours are ultimately related to student performance through their interactions with other people, most notably teachers'. They model the leadership behavioural pattern as a 'reciprocal-effects model'. They state that it reflects the reciprocal nature of the interaction of leadership, intervening variables, and student achievement, and suggest various interactions through which principals might exhibit leadership behaviour in schools over time'. This instigates leadership maintenance and generates the mirror effect that enables the PSP parameters to appropriately maintain these variations in parameters through leadership competences. Perhaps Yulk (2008) concurs that the competency of leadership lies in understanding the situation by adopting a 'flexible leadership style' for effectiveness.

This study on leadership behaviour was framed as a case study to identify and explore the behavioural leadership style incorporating the relations- and task-oriented behaviour of primary school leaders in Finland. The study uses behavioural leadership theory as developed in the work done at Ohio State University and the University of Michigan. Therefore, the purpose of this study was to explore the dominant leadership behavioural style (relations- or taskoriented) in accommodating changes and development. This study aimed to identify these leadership behavioural styles through two research questions:

1. What was the dominant leadership behavioural style either relations- or task-oriented - implemented by school principals in schools during a time of change and development?

2. How was the leadership behavioural style initiated to accommodate changes and development in schools?

\section{Methodology}

This research is explored through a qualitative paradigm. This study explores examples of school leadership represented in a case study of the three primary schools in Finland. Cases of each school's leadership were developed to understand leadership behavioural pattern in line with leadership behavioural theory, consisting of relations- and task-oriented behaviour.

\section{Theoretical constructs}

This qualitative exploration of leadership in Finnish primary schools uses leadership behavioural theory as the theoretical framework for this study. Leadership behavioural theory was introduced after the traits theory of leadership and refined to include task-oriented and relations-oriented leadership behaviour. Leadership behavioural theory was explored by Ohio State University and the University of Michigan, with the development of the Leader Behavioural Description Questionnaire (LBDQ), which has come to be widely accepted within the leadership studies discourse Stogdill (1963).

The revised form of LBDQ developed by Ohio State strongly emphasised the two factorial definitions of 'consideration and initiation' (Stogdill 1963), which were later studied as relations- and task-oriented behaviour. LBDQ initially was constructed to establish the behavioural style of leadership with the organisational managers and the supervisors to describe the behaviour of leader.

This exploration of leadership behavioural styles within Finnish primary schools is supported by task-oriented and relations-oriented probes similar to the LBDQ, but using a qualitative paradigm. This was obtained by constructing a 
factorial definition that incorporated the leadership description questionnaire that supported relations- and taskoriented behaviour, accordingly. The description of the questionnaire was obtained by interviews to give a qualitative meaning. This factorial definition was also applied to code the interview data that gave meaning to the leadership behavioural style of relations- and task-oriented behaviour.

However, these two components of leadership behaviour are not mutually exclusive, but rather complement each other. In accordance with the framework of leadership behavioural theory, this exploration of leadership is viewed as different cases with multiple examples representing each case in its own context. However, school leaders are the gap fillers, intertwining external and internal variations to harmonise the school contextual environment.

In this study, leadership behavioural theory was used to identify and explore relations- and task-oriented behaviour, and investigate the dominant leadership style in the case studies presented here. Rajbhandari (2013) explains that, although these two leadership behaviours are not mutually exclusive, one can dominate depending on immediate contextual variations and/or on leadership contextual intelligence and contextual experiences. In addition, this study explores the leadership behavioural theory by analysing the school context that affects leadership and followership.

\section{Research tools and research participants}

This study was conducted using one-to-one in-depth interviews. Two interview schedules were designed separately to explore the leadership behavioural style. One interview schedule was used to capture the perceptions of the three school leaders; and the other to capture the ideas of 10 teachers, one administrative staff member, two vice principals, and one special-education teacher from primary schools in Finland from different locations. Altogether, 17 participants were interviewed in order to understand the leadership behaviour through the perceptions of both leaders and followers in the primary schools. This set of interview schedules enabled verification through a triangulation of the data collected from the different respondents.

One-to-one interviews were conducted with different respondents from three primary schools for a minimum of an hour each, although many were extended for up to a maximum of 2 hours. Interviews were tape-recorded and later transcribed and translated for accuracy.

Based on the LBDQ, qualitative descriptions were obtained from schools leaders and followers in the three schools in Finland. The qualitative descriptive interview schedules were conducted as two scheduled interviews to obtain the perceptions of school's principals about their behaviour towards their followers while the other sets of interview descriptions were obtained to view the leadership behaviour from the perceptions of teachers, administrative staff, and a special-education teacher. Both views were cross-verified to construct a leadership behavioural pattern by using the factorial definition to incorporate the relations- and taskoriented behaviour.

\section{Data analysis procedures}

The tape-recorded data from the interviews were carefully translated and analysed to explore patterns of leadership behavioural style. The data were coded into two main themes: relations-oriented and task-oriented behaviour. Data analysis also sought to identify a third theme, a mixture of both these leadership behavioural styles. The data from the interview respondents were also compared and contrasted to minimise the occurrence of misrepresentations.

This comparison allowed a level of triangulated data sets within each case, which enhanced the validity and reliability of the analysis to understand the leadership behavioural pattern. Interviews with the principals and schools actors were cross-verified before drawing conclusions. Data sets from each school were also compared in order to explore the case study. Data triangulation analysis offered validation and reliability. This technique of data triangulation analysis contributed significantly to the validation of this investigation of leadership behavioural style. The triangulation analysis also offered similar views of respondents' answers and their reflections on leadership behaviour, which further enabled analysis of the behavioural patterns.

The interview data were coded using short phrases and a symbolic summary to illustrate the leadership behavioural pattern, which consisted of relations, task, and a mixture of both. In some cases, single words were coded to illustrate the leadership behavioural pattern, which was also observed during the study. However, observation was not the primary research tool, even though it offered huge advantages when transcribing and coding the interview data. This was followed by the display and reduction of data displaying, and the process of drawing conclusions, which further generated meaning from the data.

With regard to ethical considerations, all key respondents remained anonymous and pseudonyms were given, such as principal, vice principal, teacher 1 , teacher 2 , teacher 3 , teacher 4 , special-education teacher, and administrative staff. The schools were named as school A, school B, and school C.

\section{Results}

In this section, three primary school cases from Finland are illustrated to exemplify the leadership behavioural styles. The cases of three schools illustrate the leadership behavioural style according to leadership behavioural theory focusing either upon 'task-oriented, relations-oriented behaviour or the combinations of both' (Hersey \& Blanchard 1977). The results of these cases are reflected by the key respondent's principles as leaders, teachers, vice principals, administrative staff, and special-education teachers. The collaborative views 
reflect the triangulation analysis used to capture the leadership behavioural styles. The cases are divided between three schools' cases to address the research questions in line with the problem statement and the purpose of the study.

\section{Leadership behavioural style leaping school forward case of school A}

In complementing leadership behaviour with skills and competencies, Goff (2003:16) states that leaders should also consider using trusted staff. Using trusted staff requires leadership to show consideration towards their staff's behavioural patterns to motivate them towards task accomplishment. Coming to know and understand the staff in a school organisation can be accomplished by getting involved with them and building good relational behaviour. In the case of the principal of school A, her benevolent character led her to become successful and trusted as she initiated relations-oriented behaviour with her staff over time. The following quote illustrates her behavioural style:

'I am not being strict, concern for staff well-being is important in school and it's important to listen to them, being a head of the school.'

She further reflects on her behavioural style by stating:

'I am a cooperative person and I seek teamwork, I don't believe in working alone, and it has been beneficial for us so far.'

The relations-oriented behaviour of the principal inspired the professional staff to collaborate with the principal at a time of change in the school. Moreover, the principal closely collaborated with the vice principal during the change, acting and speaking with openness, as well as sharing with every staff member. The vice principal states:

'We have tried to develop the school so one should be able to share and talk about problems also; being able to figure out the outcome is great with some kind of teaching methods. There should be an open environment and we try to emphasis it by our own behaviour.'

Focusing on the principal's behavioural approach for effectiveness, her strategy was to influence her staff through information sharing. This behavioural pattern of the principal built a strong foundation of trust with her employees through this information sharing, as the vice principal mentions:

'She wants shared leadership, she wants to share as much as she can but still she also wants to have it all, kind of done, so that she can say that this is what I do. She always takes responsibilities about the decision even those that are made by the staff or by me.'

Information sharing is an effective means of building trust among a school community. Moreover, information is shared with those who are trusted. In an educational organisation, trust comes with an instrumental and value-based attitude. Being trusted and able to trust people is not simple. Leadership's confidence and power to communicate a vision and give direction to trusted individuals and groups is important at a time of dramatic change. According to the administrative staff, the principal had an open policy of sharing information and trusting her staff, and she adds:
'One important thing about her is she gives us all the information, a lot of information, and also I think she also trusts her staff.'

Trusting the staff and being trusted generated effectiveness. This leads to an open social environment that further reflects a good organisational climate. The relational behavioural pattern of the principal enabled the staff to share their problems even more openly. Teacher 1 mentions:

'She is very open-minded, she always tells what she thinks and if there is a problem she says it straight away and then discusses it, so I can trust her and I can go and tell her whatever problem I have, anytime.'

Whether task-oriented behaviour and relations-orientation behaviours are mutually exclusive or not, leaders concerns can vary while measuring the feelings, emotions, and level of trust throughout the professional community. However, leadership behaviours are flexible in nature and influenced by the context and the intelligence of the leaders. The adaptation to a 'flexible leadership' (Yulk 2008) behavioural pattern enables school leaders to implement a mixture of leadership styles. The mixture of leadership styles, produced by the mixing of both task-oriented behaviour and relationsoriented behaviour, leads to excellent productivity. The vice principal reflects on the principal's behavioural style towards task and relations by mentioning that:

'[Her] strongest point is that she never leaves you alone no matter whether it is a teacher, a student, or a parent.'

The behavioural pattern of a leader also depends upon the situational paradigm. The situational context of school A was to change the school into an international school. This change was introduced by the educational authorities. In order to bring about this development, and raise the school to international standards, the school leadership's role was focused on motivating and encouraging the school actors. Driving them towards adapting to the changes required through both relations-oriented and task-oriented behaviour. However, many teachers had difficulty adapting. To harmonise the organisational climate, the principal's driving force was highly focused on collaboration by implementing a relations-oriented behavioural style.

The relations-oriented behaviour of the school leader motivated the staff to work. In other words, by showing consideration, and participating and supporting staff members, the principal showed effective relations-oriented behaviour. According to teacher 3, the school principal was supportive towards them at their time of need and it contributed to their work values. Teacher 3 states:

'I have to say that it was exactly the principal who has been the most supportive here.'

A relations-oriented behavioural pattern of leadership has become a dominant approach for most leaders. In this regard, a flexible leadership approach is essential. Nevertheless, both task and relations are inseparable phenomena in an organisational setting. In addition, the behaviour of the 
followers also plays a vital role in shaping leadership behaviour. The leadership behavioural style changes according to the behavioural pattern of the followers. Leadership behaviour is, therefore, closely associated with the followers' behavioural pattern.

The relations-oriented behaviour of school A's principal was essential for team-building and bonding, in order to stimulate collaboration and drive. The principal's strategy towards relations-oriented behaviour was necessary in order to enhance the teamwork needed to overcome the restraints posed by the status quo. Teacher 3 indicated the importance of the principal's role in the school as a mediator and collaborator.

'She is supportive to all staff and arranges meetings time to time, gives us information about the progress, and initiates us to work together, which she always tell us, teamwork can yield.'

Although the principal's concern with showing considerate behaviour was high, she used task-oriented behaviour to drive development within the school, such as the renovation of buildings and changes in the curriculum. Having too much concern for employees can sometimes divert from real work being accomplished, and may create weakness rather than strengths.

The principal's versatile behavioural approach to 'leaping towards' in order to achieve the vision of the educational authority, was initiated through bonding the relations with individuals and teams. The leadership behavioural approach of delegating some of her tasks to trusted members also enabled the leap towards school succession.

In addition, the vice principal mentioned that the delegation of authority to the members allowed her more time to concentrate on daily routine work during the school's developmental phase. The relations-oriented behaviour of the principal also demonstrated her competence in keeping the driving forces active by acknowledging the teachers. This acknowledgement motivated the teachers to perform in order to keep up with the changing scenario. Team-building was important for the school leader, as it enabled her to accomplish the mission of internationalising the school. The participative and supportive nature of the principal also resulted in enhanced performance from staff, because being appreciated reinforced their motivation.

In Finland, appreciating and complimenting is not really part of the culture. However, with the relations-oriented behaviour, the principal encouraged and motivated the teachers and administrative staff by commending them on their work. The relations-oriented behaviour of the principal in school A enabled her to win the trust of the school actors. Teacher 2 states her views on trusting her principal by saying:

'I can rely on her and I respect her, and she has guts and she is a sharp decision maker when needed. I like that because we have 50 teachers and you have to have this character.'
The leadership approach of combining important factors such as, time, task, individuals, and groups was achieved by communicating the vision and generating trust-building among and between actors. However, the leadership approach of ensuring task accomplishment within academic areas was delegated to the vice principal.

The strategy of a relations-oriented leadership approach to retain constancy during a time of change was practised by the principal, while task-oriented behaviour was delegated to the vice principal in order to ensure task accomplishment.

\section{Leadership behavioural style leaping school forward case of school B}

Batagiannis (2011:1324) states that effective leaders must establish a leadership identity that includes analysing the deep transformative issues of learning and leading. For Currie and Lockett (2007), the four components of transformational leadership are charisma, inspiration, individual consideration, and intellectual stimulation. These transformational leadership components are supported by leadership flexibility that enables relevant and adaptive behaviour with respect to task or relations.

Task- and relations-oriented behaviours are not mutually exclusive, but rather, in combination, reflect the flexibility of leadership style. Hersey and Blanchard (1977:41) state the four leadership behavioural approaches of task-oriented behaviour, relations-oriented behaviour, task- and relationship-oriented behaviour, and neither task- nor relationship-oriented behaviour.

Most school leaders attempt to adapt their behaviour to combine both task- and relations-oriented behaviour. However, the relations-oriented behaviour is sensitive, emotional, and attitudinal, and allows a leader less flexibility. On the other hand, task-oriented behaviour promotes effectiveness and organisational performance. Balancing the combinations of task-oriented and relations-oriented behaviour is essential in maintaining a harmonious and effective organisational climate.

In addition, 'Driving Leadership Style' incorporates the pragmatic approach of toning, timing, transforming, tasking, and teaming as essential ingredients for school leaders to understand the micro-, meso- and macro-aspects of schools (Rajbhandari 2012). This can be achieved by implementing a combination of both task- and relationsoriented behaviour.

The principal of school B's behavioural pattern can be described as high on task- and low on relations-oriented behaviour. The principal illustrates her behavioural style as:

'The Finnish way of doing things is always democratic but sometimes it's important to be authoritative when deciding difficult matters, especially when a decision needs to be implemented on time; this require strictness in work but I also have to understand the teachers' feelings.' 
In addition, the views of special-education teacher 1 support an argument for the school principal's task-oriented behaviour:

'She is more far from our daily work but she has to have everything in her hands. And I think her main idea is that we have to be treated equally and she is working a lot and she expects it also from us. I think she demands quite much from us, but she is an example herself. But she cannot be very much involved with our lessons.'

The vice principal views the school leadership's task-oriented behaviour as:

'She is demanding but I like that; she likes that things are organised and structured but she also sort of demands that things are taken care of but, of course, there are clear responsibilities and everyone, first of all, is conscious about what their responsibilities are and carries them out and does not depend so much on people.'

A task-oriented behavioural style is important for implementing the matter-at-hand when it requires immediate action. This initiates autocratic behaviour, which enables the leaders to demonstrate their ability to act. The principal states:

'I do not have a democratic way to deal with people but I should have and I have tried. The reason I try to become strict is because everyone has to change position to get out of the comfort zone and work harder, which is important for the school.'

Having reflected on her task-oriented behaviour to leadership, the principal also displayed relations-oriented behaviour when working with people. In dealing with her staff, the principal still demonstrated task-oriented behaviour by working harder herself, by way of setting an example for others. However, the principal does have a strategy of managing people by adapting her usual management style by walking around and interacting with staff. Teacher 1 supports this view on the principal's relations-oriented behaviour:

'She is very reliable, she is very demanding but very reliable; if we talk about something now, it will be the same next week. There aren't any new ideas that make her change her opinion. I like the way she looks around and summarises. She can process things quite well and handle them and reach a conclusion.'

Moreover, Batagiannis (2011) has stated that leaders should take note of transformative issues around learning and leading. An example is the relations-oriented behaviour of the principal as she adapts her management style by walking around. According to transformational leadership theory, intellectual stimulation was provided by showing consideration to people, greeting them on the way while walking around, and judging the relevance of task performance to organisational effectiveness.

In addition, the principal's strategy of managing people while walking around also provided her with opportunity for building relations and sharing information. Teacher 3 mentions:
'I think our principal seems to have time for everybody because people usually stop her in the corridor and want to ask something, but she never looks busy and she is so confident and calm.'

Moreover, the school principal's dedication to work and her reliability have significantly contributed to developing trust among the teachers and administrative staff. In connection to this, teacher 2 mentions:

'She is a very peaceful person and kind, I trust her in the financial things and I think it is quite important in her job that I trust her and maybe she trusts me.'

Despite rating low on relations-orientation and high on taskorientation, leadership effectiveness is measured by the outcome of the combined behaviour. The principal's effectiveness is, therefore, a consequence of her ability to assess a situation and transform it through intellectual stimulation. Reflecting on this, teacher 2 admits:

'My experience is that she listens to me as I speak and she doesn't add anything between the lines and for me it's quite okay that she is also demanding. I need the feeling that I am in a group of experts.'

Many times, principals are transferred between schools with the expectation of stimulating progressive development in the school. However, the success of a school depends heavily upon their leadership skills, intellectual ability, and behavioural factors. Leadership behaviour is influenced by the context and the cultural atmosphere of the school organisation and the legacy left by former leaders.

Legacy has a strong impact on cultural binding; therefore, new leadership brings a new culture. Leadership approaches can have an impact on initiating a change in the culture. A leadership behavioural pattern that is high on task-oriented behaviour resulted in this principal being able to put things together and delegate authority.

During this phase of settling into the new setup of an organisational structure and eliminating the legacy left by the former principal, the newly appointed principal had to centralise power and delegate only if necessary, and to trusted staff. The vice principal describes the behavioural approach of the principal with respect to accountability and responsibility, when it came to re-engineering the school structure, as:

'She did everything too fast, because with the previous principal, of course, he didn't take the leadership role even though leadership has to be taken and, of course, it went somewhere else, it went to, for instance, the group of mathematicians or to the group of Finnish or English teachers, so there was power spread all over when this present principal came to this school. So it was clear she took the leadership, she made it very clear and, of course, there was opposition because these groups were losing their power and they were used to this situation. They could say, "I don't agree with you so I won't do this", with the previous principal, whereas with this principal, it is, "I don't agree with you, but I will do it".' 
This task-oriented behaviour resulted in leadership adapting an autocratic leadership style. Nevertheless, an autocratic style of leadership does not necessarily have to involve direct instruction to the staff in an organisation. It can influence working behavioural attitudes by encouraging the employees to follow by example. In addition, the vice principal describes the behavioural approach of the principal by stating:

'She is with all of us but if you have to tell what her priorities are then, I think there are matters and things and processes accordingly stated in the educational guidelines and law.'

Teacher 2 supports this view by stating:

'We were in the situation in which we needed a strong director and I think she was the one.'

Having the right balance of task-oriented behaviour and relations-oriented behaviour is difficult. However, doing things right was an urgent matter in order to enhance effectiveness. In supporting the view of the vice principal, teacher 1 admits that the principal's leadership behavioural approach showed a high task- and a low relations-orientation:

'I think this experience has led many of my colleagues to the feeling that she is too strong, very often in her position, she has to look at the wholeness and sometimes it is not what an individual would expect. And that makes situations often a bit complicated.'

In addition to autocratic behaviour, the principal also demonstrated democratic behaviour, which indicates relations-oriented behaviour. Moreover, since the principal was most often indulged in the working atmosphere, this relations-oriented behaviour was suppressed. Most importantly, the Finnish way of showing good relationsoriented behaviour is to provide the employees with space and trust them with their work. Appraisals and compliments are not appreciated by Finnish employees.

The principal of school B adopted task-oriented behaviour due to the contextual setting of the organisation left behind by the former principal. The legacy of the former principal created disruption resulting from the unwise delegation of power to the employees. Therefore, to reclaim and centralise power, the principal's strategy was to reengineer structural reform and further decentralise accountability into the most suitable hands. This strategy enabled the school principal to exercise an autocratic style of leadership by adopting taskoriented behaviour.

\section{Leadership behavioural style leaping school forward case of school C}

Leader behaviour is acceptable and satisfying to subordinates to the extent that the subordinates see such behaviour as either an immediate source of satisfaction or instrumental to future satisfaction (House 1996:325). With the behavioural pattern of leadership, the two styles - leadership taskoriented and relations-oriented - are not mutually exclusive as they can be combined in various ways. It is important that each of these behavioural styles may be effective depending on the size of the organisation, the people's clarity about their roles, and the maturity of the staff (Leithwood et al. 2006:26).

In relation to the styles of leadership behavioural theory, the principal of school C displayed and focused on task-oriented behaviour for achieving effectiveness. In connection to taskoriented behaviour of the principal, teacher 2 states:

'I think she wants to control and she wants to kind of be on that leader position that perhaps she doesn't feel that she has that position naturally because she wants to keep some kind of distance from the teachers.'

School effectiveness depends upon leadership effectiveness. This brings about school success and, consequently, leadership success. This effectiveness and success also depends on a systemic approach that enables the school's actors to follow the standard operational procedures, eventually reducing social and cultural influences, and enabling staff to focus on schools policies only. The principal of school C admits that leadership behavioural style is authoritative:

'I stand with the teachers and administrative staffs when they follow the rules and regulations that allow the school to grow. I demand more from myself than I demand from others because we have to be children-focused and that's how we can grow together, but this doesn't make people happy.'

Accordingly, does task-oriented behaviour inevitably results in an autocratic leadership style? In the case of the school C's principal, her style reflected autocracy, centralising power, and politicising it according to her will. However, the principal also had a supportive nature for those who performed their jobs. Reflecting this, teacher 3 mentions:

'Our principal is very strict and I think that if you are lacking or don't do your work, you will be in a lot of trouble with her and I also have a feeling that she is also fair, that if you do your work the way you are supposed to do it, you get support from her and that is very important especially nowadays. Some parents are really difficult. The principal has to stand behind teachers if everything is done properly, so that if you are threatened or bullied by the parents, your own boss is supporting you.'

With this autocratic style of task-oriented behaviour, the principal centralised the power because the previous principal had spread it. Despite this, she believed the educational authority required that power be distributed according to the definition of the principal's roles and responsibilities. Moreover, the principal experience also influenced her ability to manage the people in the organisation, which depends largely on the culture and the size of the organisation. Teacher 3 states:

'She wants to keep all the strings in her hand, she wants to control everything. The previous principal wasn't like that; he delegated all the matters he didn't want to do or he didn't have time to do for people. He gave jobs not, as if to say, 'You need to do this', but rather that he trusted the teachers and the vice principal and the school secretary do those things better than he would do them. But this principal wants to do everything by herself. She does everything by herself and she is working from 7 until 7.' 
Concentrating on the task does bring effectiveness. However, the school leadership also has to realise the importance of people working as a team in the organisation. The employeecentred behaviour has more to offer with respect to the motivation of employees. However, for school C's leader, task-oriented behaviour was adopted in the initial phases. The success of leadership depends highly upon the leadership's behavioural pattern. When working with mature teachers, relations-oriented behaviour can generate motivation. However, to initiate the policies and rules in the school, a high task-oriented behaviour is essential. Teacher 4 mentions the principal's autocratic behaviour:

'She demands a lot and she makes sure that everybody is doing their best always or at least the duties. She is very strict with the rules. The rules we get from the state have to be followed absolutely, everything, and we have to fill in the papers on time, and she is really strict with these things, so in that sense she demands a lot. She works a lot herself and that's why she demands a lot from others as well.'

In addition to an autocratic style and a task-oriented behaviour, the principal did maintain some level of professional relations with the employees to bring about a conducive working environment. Moreover, working with mature teachers requires professional relations that generate teacher satisfaction. Teacher 1 explains this professionalism at work:

'We have, so far, a good working relationship and teachers here in Finland have a lot of freedom to think the way they want to and we have good relationship with other teachers, getting on very well together and everyone respects each other, and you know, you get on better with teachers better than other teachers, but everyone has a good professional relationship at least. Of course, yeah, she has to have a good professional relationship, doesn't mean we have to be best friends, professionalism is very important.'

For the school leaders, on account of professionalism, staff confidence grows with the ability of leadership to adapt taskoriented behaviour. Task-oriented behaviour requires immense knowledge of how to work with people, which builds confidence in the leadership process. The philosophical views of leadership; leadership's confidence at work; professionalism, communication, transformative vision, and trust in employees, all promote trust among the employees and a willingness to work as a team within the organisation. However, with the principal of school C, her philosophy of leadership promoted confidence and trust in only a few employees.

When working with mature employees, trust is the important factor for leadership success. The principal implemented a task-oriented behaviour with confidence, supported by her experience. In relation to the confidence of the principal and her experience, teacher 2 adds:

'She is confident in her own way of working and I think perhaps she is the kind of person who wants everything to be perfect, everything to be handled the way she likes it and so that's why she is doing all the work by herself, she knows what she is doing.'
With respect to trusting employees, teachers felt that the principal did not yet understand them and that her trust of employees was very low. This reflects the principal's inclination towards high task-oriented behaviour and her attempt to maintain control and keep power within her reach. Teacher 4 indicates the principal's apparent inability to trust her employees by saying:

'She tries to control and tries to understand everything, she makes us feel that we are not trusted, but I don't think that's a problem.'

However, because of this low level of trust, the teachers were sceptical. In addition, they had been burdened with additional work over and above that stated in the rules set by the educational authority. This extra workload related to the additional reporting and administrative tasks required by the principal. The commitment of teachers was reflected in the principal's efforts to encourage employees to adapt their attitudinal behaviour.

Moreover, the teachers expected leadership to demonstrate considerate behaviour. The teachers admitted a relationsoriented behaviour from the principal would improve motivation and therefore commitment. The principal's taskoriented behaviour contradicted teachers' expectations as they expected principal participation and support. According to Hersey and Blanchard (1988), the combination of leadership's relations- and task-orientations produced the right amount of positive energy for motivation, commitment, and a good climate in an organisation.

According to Boyle (1995:71), personality contributes to behavioural tendencies and influences differences in attitudes, orientation, and decision-making styles. In connection with behavioural tendencies, the principal of school C centralised power through her task-oriented behaviour, which was carried out according to district educational authorities. For the principal, the purpose of her initial phase at the school was to develop the structural foundation and correct the uneven distribution of power allocated to the teachers and administrative staff by the previous principal. Structural changes were of utmost importance. Her emphasis on task influenced teachers' commitment, making them more responsible and accountable.

Taking into consideration time, tasks, and individuals, the principal focused on task and time. Consequently, the initial phase of establishing the structural foundation required immense task and time orientation. This strategy by the school principal was important in initiating task-focused teamwork. Moreover, enabling task-oriented behaviour was necessary in order to develop formal structures, while distributing authority at a later stage.

\section{Discussions and conclusion}

The leadership behavioural styles of school leaders in terms of both task-oriented and relations-oriented behaviour are 
not mutually exclusive. In accordance with leadership behavioural theory, as developed by researchers at Ohio State University and University of Michigan, I explored the leadership behaviour in the two frames of task-oriented and relations-oriented; and which orientation enabled the leaders to demonstrate their best competences in leaping forward. An effective leadership behavioural style, whether task- or relations-oriented, is essential for a school to leap forward. Consequently, leadership success is closely associated with school success. Therefore, leadership flexibility is important to enable leaders to remain mobile.

In the case of school A, the school leader demonstrated high relations-oriented behaviour, which significantly contributed to the school's ability to leap forward. However, in the other two cases of school B and school C, the school leadership was more inclined towards task-oriented behaviour. Nevertheless, in all the cases of school leadership explored in Finland, both relations-oriented and task-oriented behaviour contributed equally to school improvement.

The results suggest that the correct leadership behavioural style to enable a school to leap forward depends on situational demands and the practical intelligence of the leader to understand these demands. The results also suggest that a relations-oriented leadership behavioural style is less flexible than that of a task-oriented behavioural style. This is supported by Rajbhandari (2013), who found that leadership elasticity is higher in task-oriented leadership behaviour than in relations-oriented behaviour. The results corroborate his findings that a task-oriented behavioural leadership style is more effective, while a relations-oriented behavioural style is more efficient.

In this study, it was found that, in the case of school A, leaping forward was achieved by the principal's democratic leadership style, specifically focused on relations-oriented behaviour. However, in the other two cases of school B and school C, an autocratic leadership style displaying taskoriented behaviour enabled the school to leap forward. Nevertheless, both leadership behavioural styles were successful, depending upon situational factors in the school environment.

In the case of school A, the school principal had worked for a longer tenure in the same environment, which enabled her to understand variations in the organisational context. It was easy for this school leader to understand the environment and the followers' behavioural patterns. However, in the case of schools B and C, both school principals were newly appointed, which required of them to understand the contextual variations within the new environment before they could focus on relations building.

In addition to this, the school principals of schools B and C were both enabled to grow professionally as leaders within these new environments. In both cases, the legacy left by the former principals created challenges for the new principals in that they had to reengineer and restructure the staff's behavioural patterns. The contextual variations produced by the appointment of a new principal included additional variations in the context. This also suggests that contextual variations can occur by themselves, which is also considered a prime variable in the organisational context.

Moreover, a new context with a new leader can bring about extreme variations, as does the introduction of new educational policies, which need to be addressed by applying a referee leadership style (Rajbhandari 2013). In the three schools explored in Finland, contextual variations were inevitable, which required the school leaders to focus on developmental advancement, implying the referee leadership style by analysing the immediate contextual problems in the school contextual settings.

The variations that occurred in school A were initiated by the transformation of the school into an international school, which was initiated by the municipality, and the implementation of special-education law in educational policy. In schools B and C, the implementation of specialeducation law equally affected the contextual variations, as well as the re-engineering and restructuring in the organisational context.

In the three cases explored, the experienced school leader, familiar with the context (that is, school A) demonstrated relations-oriented behaviour as she was familiar with the situational context of the school organisation, including the followers, which generated efficiency at work. However, due to their unfamiliarity with the school environmental context, the principals of schools B and C adopted a task-oriented behavioural style that enabled the school leaders to remain effective with respect to task completion, even in the face of variations generated by the implementation of new policies.

A school leadership style that incorporates both the taskoriented and relations-oriented behaviour is essential to enable a school to leap forward. The findings suggest that understanding the context is critical when considering which behavioural style to adopt. The results also suggest that the personality of individuals plays a vital role in determining their behavioural pattern. Nevertheless, both relations- and task-oriented leadership behavioural styles are essential to lead the followers to productivity through motivation and commitment. These aspects are considered of prime importance to organisational development and success. The results indicate that no single behavioural style leads to successful leadership. There are aspects of individual personality and the organisational context that influence behavioural styles. Nevertheless, the findings suggest that context influenced by external forces is likely to impact leadership behavioural style. These external forces are inevitable during periods of change and development, and they influence school leadership to change their behavioural style. The findings also suggest that the importance and urgency of changes in school brought about by external forces will influence the school leadership to change its behaviour. This change in behaviour can further cause 
variations in the organisational environment. Therefore, to maintain the consistency in environmental settings, leadership behavioural pattern can play a vital role. This can further generate the maintenance of followership through leadership maintenance with PSP parameters, which is enabled by the right balancing of relations and task-oriented behaviour.

The leadership behavioural pattern enables the leaders to demonstrate leadership competencies by understanding the nature of organisation and their followers. Since good leaders are always judged by their relational approaches, it is equally vital for the leaders to demonstrate task-oriented behaviour for organisational effectiveness, even though this approach is not completely desired by the followers. Moreover, the right balancing of the leadership behavioural pattern must be demonstrated to gain leadership competences.

It is important that changes and development in schools anchor the schools' leaders, for which changes in their behavioural style are essential. Therefore, flexibility in leadership behavioural style is essential in order to fill the gap of behavioural style discrepancies. Consequently, leadership behaviour is also shaped according to the contextual environment of educational settings. This context is either generated from within or brought about by external policies. Nevertheless, these forces have an important role in shaping and reshaping leadership behaviour. Therefore, the dominance of leadership behaviour, whether relations- or task-oriented, depends on the impact of the external environment on the present contextual settings.

\section{Acknowledgements Competing interests}

The authors declare that they have no financial or professional or personal interests that may have inappropriately influenced the writing of this article.

\section{Authors' contributions}

M.M.S.R., the lead author, was responsible for constructing the theoretical framework, conceptual drawings, analysis, and incorporating the theories of leadership in educational settings in result and discussions. S.R. performed the methodology sections by data transcribing, translating, and matching the meaning to the voice of the respondents; and data reduction and displaying. C.L. was responsible for methodology. All three authors, M.M.S.R., S.R., and C.L., participated in rigorous discussions about the theoretical construction and linkage of leadership theory into educational settings.

\section{References}

Appalachia Educational Laboratory, 2005, Shared leadership and student achievement, Research brief, EDVANTIA. Inc., Appalachia Educational Laboratory, Nashville, viewed 16 Oct. 2014, from http://files.eric.ed.gov/fulltext/ED504050.pdf

Bass, B.M., 2008, The Bass handbook of leadership. Theory, research and managerial applications, 4th edn., The Free Press, New York.

Bass, B.M. \& Stogdill, R.M., 1990, Hand book of leadership theory, research and managerial applications, 3rd edn., The Free Press, New York.

Batagiannis, S.C., 2011, 'Promise and possibility for aspiring principals: An emerging leadership identity through learning to do action research', The Qualitative Report 16(5), 1304-1329, viewed 22 Dec. 2014, from http://eric.ed.gov/PDFS/EJ941707.pdf

Bolden, R., Gosling, J., Marturano, A. \& Dennison, P., 2003, A review of leadership theory and competency frameworks, Centre for Leadersihp Studies, viewed 13 Apr. 2015, from http://www2.fcsh.unl.pt/docentes/luisrodrigues/textos/Lideran\%C3\%A7a. pdf

Boyle, G.J., 1995, 'Myers-Briggs Type Indicator (MBTI): Some psychometric limitations', Australian Psychologist 30, 71-74. http://dx.doi.org/10.1111/j.1742-9544.1995. tb01750.x

Currie, G. \& Lockett, A., 2007, 'A critique of transformational leadership: Moral professional and contingent dimension of leadership within public services organizations', Human Relationship 60(2), 341-370, viewed 03 Jan. 2015, from http://hum.sagepub.com/content/60/2/341

Derue, D.S., Nahrgang, J.D., Wellman, N. \& Humphrey, S.E., 2011, 'Trait and behavioural theories of leadership: An integration and meta-analytic test of their relative validity', Personal Psychology 64, 7-52. http://dx.doi.org/10.1111/j.17446570.2010.01201.x

Goff, D.G., 2003, What do we know about good community college leaders: A study in leadership traits theory and behavioural leadership theory, Research report. ED476456, viewed 22 Mar. 2015, from http://files.eric.ed.gov/fulltext/ED476456.pdf

Hersey, P. \& Blanchard, K.H., 1977, The management of organizational behaviour, 3rd edn., Prentice-Hall, Englewood Cliffs, NJ.

Hersey, P. \& Blanchard, K.H., 1988, The management of organizational behaviour, 5th edn., Prentice-Hall, Englewood Cliffs, NJ.

House, R.J., 1996, 'Path goal theory of leadership: Lessons, legacy and a reformulated theory, The Wharton school of management', Leadership Quarterly 7(33), 323-352. http://dx.doi.org/10.1016/S1048-9843(96)90024-7

Leithwood, K., Days, C., Sammons, P., Harris, A. \& Hopkins, D., 2006, Successful school leadership: What it is and how it influences pupil learning, Research report, RR 800, Department for Education and Skills, University of Nottingham, DfES Publications, Annesley, Nottingham.

Likert, R., 1967, The human organization, McGraw-Hill Book Company, New York.

Northouse, P.G., 2010, Leadership. Theory and practice, 5th edn., Sage Publication, Inc., Thousand Oaks, CA.

Rajbhandari, M.M.S., 2012, Growing with driving leadership style in school: A case study on leadership of Finnish elementary schools in Tampere, School of Education, University of Tampere, Tampere, Finland, ED532213, viewed 01 Dec. 2014, from http://eric.ed.gov/PDFS/ED532213.pdf

Rajbhandari, M.M.S., 2013, 'School leadership en-route to grand leap. Case studies from Nepal and Finland', ISBN: 978-951-44-9235-8, viewed 01 Nov. 2014, from http:// tampub.uta.fi/handle/10024/94461, http://urn.fi/URN:ISBN:978-951-44-9235-8

Rajbhandari, M.M.S. \& Rajbhandari, S., 2015, 'Leadership maintenance: Filling the gap for leadership competences', Educational Research and Reviews 10(21), 2777-2788. http://dx.doi.org/10.5897/ERR2015.2336

Sahlberg, P., 2010, 'The secret to Finland's success: Educating teachers', Stanford Center for Opportunity Policy in Education - Research brief, viewed 2 October 2014, from https://edpolicy.stanford.edu/sites/default/files/publications/secretfinland $\%$ E2 $\% 80 \% 99 s$-success-educating-teachers.pdf on

Sergiovanni, T.J., 1990, 'Adding values to leadership gets extraordinary results. Educational leadership', viewed 9 September 2014, from http://www.ascd.org/ ASCD/pdf/journals/ed_lead/el_199005_sergiovanni.pdf

Sternberg, R.J., 1985, Beyond IQ: A triarchic theory of human intelligence, Cambridge University Press, New York.

Sternberg, R.J., 2000, 'Intelligence and wisdom', in R.J. Sternberg (ed.), Handbook of intelligence, pp. 631-649, Cambridge University Press, New York.

Stogdill, R.M., 1959, Individual behavior and group achievement, Oxford University Press, New York.

Stogdill, R.M., 1963, Manual for the leader behaviour descriptive questionnaire - Form XII: An experiential revision, Fisher College of Business, The Ohio State University Columbus.

Yulk, G., 2008, 'The importance of flexible leadership', in The Importance, Assessment, and Development of Flexible Leadership, Practitioner Forum Presented at the 23rd Annual Conference of the Society for Industrial-Organizational Psychology, pp1-6, San Francisco, CA. viewed 29 May 2015, from http://www.kaplandevries.com/ images/uploads/Importance_of_FL_SIOPO8Yukl.pdf 